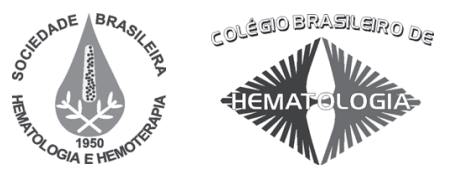

\title{
The issue of refractory disease in follicular and other lymphoma subtypes
}

\section{A refratariedade no linfoma folicular e em outros linfomas}

\author{
Marco Ruella ${ }^{1}$ \\ Angela Gueli ${ }^{I}$ \\ Alessandra Risso ${ }^{2}$ \\ Irene Ricca ${ }^{3}$ \\ Daniela Gottardi ${ }^{4}$ \\ Alberto De Crescenzo 4 \\ Roberto Passera ${ }^{5}$ \\ Marco Ladeto ${ }^{6}$ \\ Corrado Tarella
}

\begin{abstract}
The outcome of lymphoma has definitely improved over the last few decades which is mainly due to the introduction and development of novel and effective therapeutic approaches. Nevertheless, a small though notable group of patients may display a poor response to treatments, with a true refractoriness or a transient response followed by early relapse. The present review addresses the issue of refractory disease among patients with lymphoma, focusing on the overall incidence and the main clinical aspects associated with refractoriness. Rev. Bras. Hematol. Hemoter. 2009;31(Supl. 2):15-18.
\end{abstract}

Key words: Hodgkin's lymphoma; non-Hodgkin's lymphoma; chemotherapy; autologous stem cell transplantation; refractory disease.

\section{Introduction}

Hodgkin's (HL) and non-Hodgkin's (NHL) lymphomas are malignant tumors usually characterized by a high response-rate to chemo-radiotherapy. Among NHL, peculiar epidemiology features have been observed, with the incidence progressively increasing over the last 50 years up to the value of 19.5 per 100,000 individuals per year, based on cases diagnosed in 2002-2006. Indeed, the incidence of NHL has increased $0.6 \%$ per year during the period 1991-2004, while mortality clearly shows a decrease of $3.2 \%$ per year. For HL, the incidence has been decreasing slightly over the last 30 years, dropping to the value of 2.8 per 100,000 individuals per year (2002-2006 diagnoses). Again, the mortality rate of HL has shown a marked reduction, with trend rates analogous to those observed in NHL. At present, the overall age-adjusted mortality rate of NHL is 7.1 per $100,000 /$ year and 0.4 per $100,000 /$ year for HL according to the most recent survey by
SEER. ${ }^{1}$ Thus, the outcome of lymphoma has definitely improved over the last few decades which is mainly due to the introduction and development of novel and effective therapeutic approaches.

In the field of lymphoma, several treatment options have been successfully employed, including high dose chemotherapy, autologous stem cell transplantation and different classes of new biological drugs, in particular the chimerical and humanized monoclonal antibodies directed against lymphocyte-specific antigens. Progressively, a great fraction of patients can now obtain complete response, which is often durable. This results in prolonged survival which frequently means the cure of an otherwise fatal malignant disease. Nevertheless, a small though notable group of patients may display a poor response to treatment, with true refractoriness or a transient response followed by early relapse. Appropriate studies are needed to identify possible early predictors of refractory disease. This will allow the

${ }^{1}$ Università di Torino, Facoltà di Medicina e Chirurgia; Molecular Biotechnology Center, Torino, Italy.

${ }^{2}$ Molecular Biotechnology Center, Torino, Italy.

${ }^{3}$ Ospedale Cottolengo di Torino, Italy.

${ }^{4}$ A.O. Ordine Mauriziano, Div. Ematologia e Terapie Cellulari, Torino, Italy.

${ }^{5}$ A.O.U. S. Giovanni B, Div. Univ. Med. Nucl. Torino, Italy

${ }^{6}$ Università di Torino, Facoltà di Medicina e Chirurgia - Div. Univ. Ematologia, Torino, Italy

${ }^{7}$ Università di Torino, Facoltà di Medicina e Chirurgia - Molecular Biotechnology Center, Torino; A.O. Ordine Mauriziano,

Div. Ematologia e Terapie Cellulari, Torino, Italy

Correspondence: Corrado Tarella

Div. Universitaria Ematologia e Terapie Cellulari

A.O. Ordine Mauriziano-Umberto I \& Molecular Biotechnology Center

University of Torino

L.go Turati 62, 10128 Torino, Italy

Phone: 0039-011-508.2949; 670.6444 - Portable: 347-4315493 -fax: 0039-011-508.2446

E-mail: corrado.tarella@unito.it 
investigation of novel therapeutic programs suitable for patients at high risk of poor response to standard treatment approaches.

The present review addresses the issue of refractory disease among patients with lymphoma, focusing on the overall incidence and the main clinical aspects associated with refractoriness.

\section{Refractory disease in high-risk follicular lymphoma}

To evaluate the efficacy of high-dose therapy and ASCT in the treatment of Follicular Lymphoma (FL) a randomized multicenter trial comparing intensive therapy vs. conventional chemotherapy, both supplemented with Rituximab, has recently been performed in high-risk FL at diagnosis. Most Italian Centers associated to GITMO (Gruppo Italiano Trapianto Midollo Osseo) and to IIL (Intergruppo Italiano Linfomi) participated to the study. The intensive arm was the high-dose sequential (HDS) schedule, developed several years ago for $\mathrm{FL}$ and other indolent lymphoma ${ }^{2}$ while the conventional arm was the well known CHOP (cyclophosphamide/doxorubicin/vincristine/prednisone) scheme. Four to six doses were included in the HDS scheme (R-HDS) and at completion of 6 CHOP courses (CHOP-R). Overall, 136 patients were enrolled and evaluable for response to treatment. Preliminary results have been recently reported in Blood. ${ }^{3}$ In summary, R-HDS proved to have a more potent anti-lymphoma activity compared to CHOP-R, with 4-year EFS of $61 \%$ and $28 \%$, respectively $(\mathrm{P}<.001)$, at a median follow-up (MFU) of 51 months. However, this did not translate in survival advantages. Indeed, no difference in overall survival (OS) was observed between patients of the two treatment arms. Interestingly, molecular remission (MR) was achieved in $44 \%$ of CHOP-R and $80 \%$ of R-HDS patients $(\mathrm{P}<.001)$, and was the strongest independent outcome predictor.

The presence of refractory patients was clearly documented in this randomized study. As shown in Table 1, complete remission (CR) was $62 \%$ with CHOP-R and $85 \%$

Table 1. Response according to treatment arm of 136 high risk FL patients enrolled in the GITMO/IL randomized study

\begin{tabular}{lccc}
\hline \multicolumn{1}{c}{ Parameters of response } & CHOP-R & R-HDS & $p$ \\
\hline CR/Cru & $62 \%$ & $85 \%$ & $<.001$ \\
PR & $7 \%$ & $3 \%$ & NS \\
OR (CR+PR) & $68 \%$ & $89 \%$ & $<.01$ \\
Progression or stable disease & $29 \%$ & $10 \%$ & $<.05$ \\
Not Evaluable & $3 \%$ & $2 \%$ & NS \\
\hline Total $n^{\circ}$ of patients & $68(100 \%)$ & $68(100 \%)$ & \\
\hline
\end{tabular}

$\mathrm{CR}=$ Complete Remission; $\mathrm{Cru}=\mathrm{CR}$ undefined;

$\mathrm{PR}=$ partial remission; $\mathrm{OR}=$ overall response, according to Cheson's criteria of response ${ }^{22}$
Table 2. Efficacy of R-HDS in the rescue of $\mathrm{FL}$ patients progressing after $\mathrm{CHOP}-\mathrm{R}$

\begin{tabular}{lccc}
\hline Rescue Program & Total & \multicolumn{2}{c}{ CR } \\
\hline Minimal treatment ${ }^{*}$ & 11 & 6 & $54 \%$ \\
Conventional CT ${ }^{* *}$ & 8 & 6 & $75 \%$ \\
R-HDS & 24 & 30 & $80 \%$ \\
Allogeneic Transplantation & 1 & 1 & $100 \%$ \\
\hline
\end{tabular}

* Rituximab +/- Radiotherapy; **Fludarabine containing chemotherapy; R-HDS= High Dose Sequential scheme

with R-HDS $(\mathrm{P}<.001)$. The difference in the rate of $\mathrm{CR}$ was mainly due to the different proportion of non-responding, i.e. refractory, patients. In fact, approximately $30 \%$ of patients receiving CHOP-R had a poor response, displaying progressive or stable disease; poor responders were approximately $10 \%$ in the R-HDS arm. Thus, in spite of the effective treatment delivered (CHOP or HDS both supplemented with rituximab) there is still a variable, nonnegligible, group of patients displaying refractory disease. The cross-over design of the study offered a good opportunity of rescue to patients failing after CHOP-R. Indeed, patients refractory or early-relapsing after CHOP-R underwent salvage with R-HDS. As shown in Table 2, salvage R-HDS had an $80 \%$ CR rate and a $68 \% 3$-year EFS (MFU, 30 months). Thus, most patients with poor response to CHOP-R experienced a prolonged survival following R-HDS as rescue and this explains the lack of difference in OS between the two treatment arms. In conclusion, the study offered several important insights for the management of high-risk FL. In particular, it has been confirmed that achieving CR and MR is critical for effective disease control, regardless of which treatment is used; overall, R-HDS given front-line ensures superior disease control and molecular outcome than CHOP$\mathrm{R}$, but no improvement in OS; lastly, the presence of FL patients with refractory disease is a major concern, particularly with conventional chemo-immunotherapy such as CHOP-R; however, primary failures after CHOP-R have a good outcome if rescued with R-HDS. Taken together, all these aspects suggest that relapsed/refractory FL might be the most appropriate setting for R-HDS-like treatments.

\section{Incidence of refractory disease in NHL other than follicular subtype}

To increase cure rates in patients with aggressive or refractory/relapsing NHL, intensive treatments and ASCT have been extensively investigated, mostly in patients younger than 60 to 65 years. ${ }^{4.5}$ Applicability and efficacy of the HDS approach has been improved by the use of mobilized peripheral blood cells (PBSC) for the autograft procedure. ${ }^{6,7}$ Moreover, the use of agents such as the monoclonal antiCD20 antibody and rituximab (R), has markedly improved the therapeutic efficacy of ASCT-based programs by the in vivo 
purging effect on PBSC harvests, as reported by other groups and by a recent study from our cooperative GITIL (Gruppo Italiano Terapie Innovative nei Linfomi) group. ${ }^{8-12}$

In the setting of Diffuse Large B-cell lymphoma (DLB$\mathrm{CL}$ ), the GITIL group has recently completed a prospective multicenter study evaluating the rituximab-supplemented, early-intensified high-dose chemotherapy regimen, delivered with multiple autologous support using in-vivo purged PBPC, in a series of 112 previously untreated patients with DLB-CL and aaIPI 2 or 3 . Both response and long-term outcome were definitely promising, and compare quite favorably with the dismal outcome commonly observed in poor-risk DLB-CL treated with conventional chemotherapy regimens. ${ }^{13}$ Overall 90 patients $(80.4 \%)$ reached CR. However, again the major cause of treatment failure was disease progression, documented in $12(11 \%)$ patients. This is consistent with the selection of a true poor-risk patient population, with some cases displaying a highly refractory disease, unresponsive to repeated courses of high-dose cytotoxic drugs given at short intervals. Moreover, the result confirms that a variable proportion of NHL patients may be primary refractory, even to high-dose therapy with rituximab.

In order to assess the real number of NHL patients with refractory or early-relapsing disease, a recent study was undertaken to evaluate the actual rate of refractory patients. The long-term outcome of primary refractory vs. responsive patients is also under evaluation. Data have been collected on a series of 503 NHL patients referred and treated at our institutions between 1995 and 2005. The group included 461 B-cell and 42 T-cell NHL; main histological subtypes consisted of: 305 high-grade NHL, 183 low-grade NHL and 15 mantlecell lymphoma. Overall, $126(25 \%)$ patients were refractory (39\% with no response at all and $61 \%$ with short-lasting response soon followed by disease progression). The rate of refractoriness was as high as $40 \%$ in the small T-cell NHL subgroup, while the overall incidence was $24 \%$ for B-cell NHL. There was no significant difference in the distribution of refractory patients among the histological subtypes of BNHL, in other words none of the B-cell NHL subtypes was specifically associated with poorer response to treatment. The use of the HDS program as front-line treatment was significantly associated with reduced risk of refractory disease $(\mathrm{OR}=0.30)$. These data apparently suggest that better outcome could derive by an early use of the HDS approach in newly diagnosed NHL with advanced stage of disease and other typical clinical features of poor prognosis. ${ }^{14}$ Indeed, further studies are still needed, in order to identify patients unfit to receive conventional treatment due to poorly responsive disease as early as possible. For these patients, the prompt institution of alternative treatment approaches might increase the chances of achieving disease remission.

At present, therapeutic procedures available for the rescue of patients displaying overt refractory disease apparently do not improve the chance of long-term survival.
Life expectancy remains dramatically poor for patients with refractory or early relapsing disease. Indeed, in our analysis it was possible to observe that refractory patients had a definitely short life expectancy, with a median survival of 21 months and a 14 -year survival projection of $10 \%$, which is markedly worse compared to the $88 \%, 76 \%$ and $65 \%$ survival projections at 5, 10 and 15 years, respectively, of responsive patients. Several studies have shown some efficacy of ASCT in the salvage treatment of NHL. ${ }^{4,5,15}$ In addition, allogeneic stem cell transplantation is an effective treatment option which seems to improve the outcome of refractory patients, particularly since the development of the reduced intensity conditioning regimen (RIC). ${ }^{16}$

\section{Conclusion}

The results herein presented indicate that a nonnegligible proportion of NHL patients have refractory disease. Overall, refractory patients represent approximately one quarter of NHL cases undergoing induction therapy. Besides advanced stage and high LDH levels, no other clinical and histological factors are specifically associated to refractoriness; indeed, further studies are needed to identify possible molecular markers predictive of refractoriness in order to design induction therapies adapted for refractory patients given their dismal outcome with currently available treatment strategies. A lot of new small molecules that target bcl-2, bcl6, mTOR, the AKT pathway (deforolimus), P-glycoprotein (Zosuquidar), histone deacetylase (SAHA) and NF-kB have shown promising activity in preclinical and early-phase clinical studies. ${ }^{17,18}$ Moreover, a clear benefit has been documented with some new drugs or combination of drugs, including lenalidomide, bendamustine and the radiolabeled anti-CD20 Zevalin. ${ }^{19,20,21}$ New targets and new drugs should be carefully considered as an important tool in the effort to improve the very poor outcome of patients with refractory lymphoma.

\section{Resumo}

A evolução dos linfomas tem sido definitivamente melhorada ao longo das últimas décadas. Isto se deve principalmente devido à introdução e desenvolvimento de novas e efetivas abordagens terapêuticas. Apesar disto, uma pequena parcela deste notável grupo de pacientes pode apresentar uma pobre resposta aos tratamentos, com uma verdadeira refratariedade, ou com resposta transitória e precocemente uma recidiva. A presente revisão aborda este assunto da doença refratária nos pacientes com linfoma, enfocando sua incidência global e os principais aspectos clínicos associados à refratariedade. Rev. Bras. Hematol. Hemoter. 2009; 31(Supl. 2):15-18.

Palavras-chave: Linfoma de Hodgkin; linfomas não Hodgkin; quimioterapia; transplante autólogo de células-tronco; doença refratária. 


\section{Acknowledgements}

We want to thank all investigators from the Institutions in Italy associated to GITMO (Gruppo Italiano Trapianto Midollo Osseo), IIL (Intergruppo Italiano Linfomi) and GITIL (Gruppo Italiano Terapie Innovative nei Linfomi), for their invaluable help and contribution to carry out the clinical trials mentioned in this review.

\section{References}

1. Horner MJ, Ries LAG, Krapcho M, Neyman N, Aminou R, Howlader N, et al (eds). SEER Cancer Statistics Review, 1975-2006, National Cancer Institute. Bethesda, MD, http://seer.cancer.gov/csr/ 1975_2006/, based on November 2008 SEER data submission, posted to the SEER web site, 2009

2. Tarella C, Caracciolo D, Corradini P, Zallio F, Ladetto M, Cuttica A, et al. Long-term follow-up of advanced-stage low-grade lymphoma patients treated upfront with high-dose sequential chemotherapy and autograft. Leukemia. 2000;14(4):740-7.

3. Ladetto M, De Marco F, Benedetti F, Vitolo U, Patti C, Rambaldi A, et al. Prospective, multicenter randomized GITMO/IIL trial comparing intensive (R-HDS) versus conventional (CHOP-R) chemoimmunotherapy in high-risk follicular lymphoma at diagnosis: the superior disease control of R-HDS does not translate into an overall survival advantage. Blood. 2008;111 (8):4004-13.

4. Laport GF, Williams SF. The role of high-dose chemotherapy in patients with Hodgkin's disease and non-Hodgkin's lymphoma. Semin Oncol. 1998;25(4):503-17.

5. Salles G, Coiffier B. Autologous peripheral blood stem cell transplantation for non-Hodgkin's lymphoma. Baillieres Best Pract Res Clin Haematol. 1999; 12:151-169.

6. Gianni AM, Siena S, Bregni M, Tarella C, Stern AC, Pileri A, et al. Granulocyte-macrophage colony-stimulating factor to harvest circulating haemopoietic stem cells for autotransplantation. Lancet. 1989;2(8663):580-5.

7. Schmitz N, Linch DC, Dreger P, Goldstone AH, Boogaerts MA, Ferrant A, et al. Randomised trial of filgrastim-mobilised peripheral blood progenitor cell transplantation versus autologous bonemarrow transplantation in lymphoma patients. Lancet. 1996;347(8998):353-7.

8. Voso MT, Pantel G, Weis M, Schmidt P, Martin S, Moos M, et al. In vivo depletion of $\mathrm{B}$ cells using a combination of high-dose cytosine arabinoside/mitoxantrone and rituximab for autografting in patients with non-Hodgkin's lymphoma. Br J Haematol. 2000; 109(4):729-35.

9. Magni M, Di Nicola M, Devizzi L, Matteucci P, Lombardi F, Gandola L, et al. Successful in vivo purging of CD34-containing peripheral blood harvests in mantle cell and indolent lymphoma: evidence for a role of both chemotherapy and rituximab infusion. Blood. 2000;96(3):864-9.

10. Flinn IW, O'Donnell PV, Goodrich A, Vogelsang G, Abrams R, Noga $\mathrm{S}$, et al. Immunotherapy with rituximab during peripheral blood stem cell transplantation for non-Hodgkin's lymphoma. Biol Blood Marrow Transplant. 2000;6(6):628-32.

11. Belhadj K, Delfau-Larue MH, Elgnaoui T, Beaujean F, Beaumont $\mathrm{JL}$, Pautas $\mathrm{C}$, et al.Efficiency of in vivo purging with rituximab prior to autologous peripheral blood progenitor cell transplantation in B-cell non-Hodgkin's lymphoma: a single institution study. Ann Oncol. 2004;15(3):504-10.

12. Tarella C, Zanni M, Magni M, Benedetti F, Patti C, Barbui T, et al. Rituximab improves the efficacy of high-dose chemotherapy with autograft for high-risk follicular and diffuse large B-cell lymphoma: a multicenter Gruppo Italiano Terapie Innnovative nei linfomi survey. J Clin Oncol. 2008;26(19):3166-75.

13. la C, Zanni M, Di Nicola M, Patti C, Calvi R, Pescarollo A, et al. Prolonged survival in poor-risk diffuse large B-cell lymphoma following front-line treatment with rituximab-supplemented, earlyintensified chemotherapy with multiple autologous hematopoietic stem cell support: a multicenter study by GITIL (Gruppo Italiano Terapie Innovative nei Linfomi). Leukemia. 2007;21(8):1802-11.

12. Gueli A, Caracciolo D, Zanni M, Bergui L, Gavarotti P, Ladetto M, F, et al. Non-Hodgkin's Lymphoma Refractory to First Line Therapy: Incidence, Associated Clinical and Histological Factors, and Outcome among 503 Newly Diagnosed Patients. Blood (ASH Annual Meeting Abstracts), Nov 2007; 110: 1373.

13 Tarella C, Cuttica A, Caracciolo D, Zallio F, Ricca I, Bergui L, et al. High-dose sequential (HDS) chemotherapy for high-risk nonHodgkin's lymphoma: long-term analysis and future developments. Ann Hematol. 2001;80 Suppl 3:B123-6.

14. Corradini P, Dodero A, Farina L, Fanin R, Patriarca F, Miceli R, et al. Allogeneic stem cell transplantation following reduced-intensity conditioning can induce durable clinical and molecular remissions in relapsed lymphomas: pre-transplant disease status and histotype heavily influence outcome. Leukemia. 2007;21(11):2316-23.

15. Rizzieri DA, Feldman E, Dipersio JF, Gabrail N, Stock W, Strair R, et al. A phase 2 clinical trial of deforolimus (AP23573, MK8669), a novel mammalian target of rapamycin inhibitor, in patients with relapsed or refractory hematologic malignancies. Clin Cancer Res. 2008;14(9):2756-62.

16. Morschhauser F, Zinzani PL, Burgess M, Sloots L, Bouafia F, Dumontet C. Phase I/II trial of a P-glycoprotein inhibitor, Zosuquidar.3 HCl trihydrochloride (LY335979), given orally in combination with the CHOP regimen in patients with nonHodgkin's lymphoma. Leuk Lymphoma. 2007;48(4):708-15.

17. Zhang L, Qian Z, Cai Z, Sun L, Wang H, Bartlett JB, et al. Synergistic antitumor effects of lenalidomide and rituximab on mantle cell lymphoma in vitro and in vivo. Am J Hematol. 2009. [Epub ahead of print]

18. Kang BW, Kim WS, Kim C, Jang G, Lee SS, Choi YH, et al. Yttrium-90-ibritumomab tiuxetan in combination with intravenous busulfan, cyclophosphamide, and etoposide followed by autologous stem cell transplantation in patients with relapsed or refractory B-cell non-Hodgkin's lymphoma. Invest New Drugs. 2009. [Epub ahead of print].

19. Cheson BD, Rummel MJ. Bendamustine: rebirth of an old drug. J Clin Oncol. 2009;27(9):1492-501.

20. Cheson BD, Horning SJ, Coiffier B, Shipp MA, Fisher RI, Connors $\mathrm{JM}$, et al. Report of an international workshop to standardize response criteria for non-Hodgkin's lymphomas. NCI Sponsored International Working Group. J Clin Oncol. 1999;17(4):1244.

Financial Support: Part of the studies reported have been supported by grants from: Ministero dell'Istruzione, dell'Università e della Ricerca (MIUR) and the Piedmont Regional Government (Regione Piemonte).

O tema apresentado foi proposto pela Organização do $8^{\circ}$ Simpósio da Associação Ítalo-Brasileira de Hematologia, realizado durante o XIII Congresso de Transplante de Medula Óssea.

Publicado após concordância do editor.

Recebido: 08/07/2009

Aceito: 16/07/2009 